Research Article

\title{
Frequency and Predictors of Self-Reported Hypoglycemia in Insulin-Treated Diabetes
}

\author{
Samir Malkani ${ }^{1}$ and Anupam Kotwal ${ }^{2}$ \\ ${ }^{1}$ Division of Diabetes, Department of Medicine, University of Massachusetts Medical School, Worcester, MA 01655, USA \\ ${ }^{2}$ Division of Endocrinology, Diabetes, Metabolism, and Nutrition, Mayo Clinic, 200 First Street SW, Mayo 18, Rochester, \\ MN 55905, USA
}

Correspondence should be addressed to Anupam Kotwal; Kotwal.Anupam@mayo.edu

Received 6 June 2017; Accepted 6 July 2017; Published 20 August 2017

Academic Editor: Konstantinos Papatheodorou

Copyright (c) 2017 Samir Malkani and Anupam Kotwal. This is an open access article distributed under the Creative Commons Attribution License, which permits unrestricted use, distribution, and reproduction in any medium, provided the original work is properly cited.

\begin{abstract}
Aims. Hypoglycemia is a limiting factor for achieving stringent glycemic control in diabetes. This study analyzes the frequency and predictors of hypoglycemia in insulin-treated diabetes in an ambulatory setting. Methods. A retrospective chart review was performed to study self-monitored blood glucose (SMBG) data for 3 months prior to a patient's HbA1c test. Results. Hypoglycemia occurred more frequently in type 1 than in type 2 diabetes; however, $19 \%$ of type 2 diabetes patients did experience at least one episode of severe hypoglycemia. For type 1 diabetes, hypoglycemia had a positive association with glycemic variability and duration of diabetes and a negative association with HbAlc and lowest blood glucose (BG). For type 2 diabetes, a positive association was noted with glycemic variability and a negative association with age and lowest BG. Conclusions. Delineating factors predisposing to hypoglycemia in type 2 diabetes is difficult. Lower HbA1c is a potential predictor of hypoglycemia in type 1 but not in type 2 diabetes. Longer duration of diabetes for type 1 and younger age for type 2 are associated with more hypoglycemia. Glycemic variability portends increased risk for hypoglycemia and should be a focus of further research.
\end{abstract}

\section{Introduction}

Hypoglycemia is a major limiting factor for achieving stringent glycemic control in diabetes. It influences selfmanagement of diabetes with some patients accepting suboptimal glycemic control to reduce the risk of hypoglycemia [1]. Moreover, hypoglycemia is associated with significant morbidity. Severe hypoglycemia can cause seizures and arrhythmias. It is associated with dementia [2], and it has been linked with poor cardiovascular outcomes [3] and death [4]. Hypoglycemia has also been shown to trigger adrenergic discharge and the expression of proinflammatory cytokines [5].

Hypoglycemia is common in type 1 diabetes, and its occurrence increases with insulin use in type 2 diabetes [6-10]. It is a common and potentially dangerous side effect of insulin therapy; however, its occurrence is not easy to predict. The majority of our knowledge about severe hypoglycemia comes from type 1 diabetes. Data on rates and potential risk factors for severe hypoglycemia in insulin-treated type 2 diabetes are relatively scarce and conflicting. Clinical trials have reported low rates of severe hypoglycemia in type 2 diabetes $[11,12]$, and population-based studies have reported highly variable rates $[13,14]$. The reported frequency of severe hypoglycemia in clinical trials may represent only the "tip of the iceberg" in terms of all episodes. In the case of severe hypoglycemia, most studies have used its clinical definition that was first described by the Diabetes Control and Complications Trial (DCCT), as any hypoglycemia that requires external assistance [15]. However, reporting of such episodes by patients, especially those with hypoglycemia unawareness, can be unreliable. Data derived from the frequency of treated episodes of severe hypoglycemia by emergency services are similarly inadequate to quantify the overall incidence, as only $10 \%$ of severe episodes are treated in the hospital. Data from continuous glucose monitoring (CGM) 
studies reveal that even asymptomatic hypoglycemia is associated with the risk of cardiac arrhythmias [16].

In patients on insulin therapy, inadequate caloric intake, exercise, renal insufficiency, and alcohol ingestion can precipitate hypoglycemia. In many episodes of hypoglycemia, a precipitating factor cannot be identified. Although some phenotypic markers are known to predispose patients to hypoglycemia, its predictors in insulin-treated diabetes have not been well studied, especially when these patients are followed on an ambulatory basis and have not been actively enrolled in a study. Hypoglycemia unawareness is common in longstanding diabetes and can lead to serious consequences in spite of lack of symptoms, and blood glucose testing or CGM can identify such episodes more reliably. To try and fill the gaps in knowledge, we conducted this study to analyze the frequency and potential predictors of self-monitored hypoglycemia in type 1 and insulin-treated type 2 diabetes in an ambulatory setting.

\section{Material and Methods}

2.1. Subjects with Diabetes Mellitus. We performed a crosssectional chart review study utilizing the electronic database of the University of Massachusetts Medical School Diabetes Clinic. The clinic, which serves residents of central Massachusetts, uses an electronic diabetes management system, My Care Team ${ }^{\mathrm{TM}}$ (MCT) that captures all the patients' selfmonitored blood glucose (SMBG) data. The system is able to upload readings from most commercial blood glucose monitors; data from blood glucose meters is uploaded at each clinic visit. Diabetic adults who were seen at the clinic between October 1, 2012, and September 30, 2013, were eligible if they were on insulin treatment, and their meter download on MCT showed a SMBG testing frequency of 3 times or more daily. Pregnant women were excluded. The UMass IRB approved the study proposal. Of the total sample of 3000 patients, 298 were included in the study based on the eligibility criteria. Each patient had a hemoglobin A1c (HbA1c) tested at the visit, and the SMBG data for a 3month period prior to the clinic visit was collected. For patients who had more than one clinic visit during the study period, the most recent one was used for the purpose of data collection. Categorical variables assessed were gender, race, and presence or absence of depression, coronary artery disease (CAD), hypertension (HTN), nephropathy, and retinopathy. Nephropathy was defined as albuminuria (spot urine albumin : creatinine ratio $>300 \mathrm{mcg} / \mathrm{mg}$ ) or progressive chronic kidney disease, and presence of retinopathy included all classes of detectable retinopathy. Continuous variables assessed were age, body mass index (BMI), duration of diabetes, HbAlc, daily insulin dose, number of daily injections, and $\mathrm{SMBG}$ data including minimum SMBG value and standard deviation (SD) around mean SMBG.

2.2. Identification of Hypoglycemic Episodes. Hypoglycemia was defined as a $\mathrm{SMBG}$ reading $\leq 70 \mathrm{mg} / \mathrm{dL}$ [17], and severe hypoglycemia as a SMBG reading $\leq 45 \mathrm{mg} / \mathrm{dL}$. All commercial SMBG monitors provide glucose readings such that the reported result most closely matches that of a laboratory method measuring serum or plasma glucose [18]. No distinction was made between asymptomatic and symptomatic hypoglycemic episodes. We calculated the number hypoglycemic episodes for each patient from their home glucose meter upload for a 3-month period prior to their clinic visit. Sequential SMBG readings meeting hypoglycemia criteria recorded within a 2 -hour period were considered as a single episode.

2.3. Statistical Analysis. A database was created with data for all the variables, and statistical analysis was performed using the software SPSS. As the independent variables were not distributed normally, nonparametric tests of significance were utilized. Mann-Whitney $U$ test was used to assess the association of categorical independent variables with dependent variables (frequency of hypoglycemia and severe hypoglycemia). For continuous variables, Spearman's correlation and Wilcoxon signed-rank test were used for univariate analysis. $p$ value $\leq 0.05$ was considered significant. All probabilities were two tailed. Multivariate linear regression (as dependent variables were continuous) was then used for all the associations that were significant on univariate analysis to remove the effect of confounders. Two separate models were created using the frequencies of all hypoglycemic episodes and severe hypoglycemic episodes as dependent variables.

\section{Results}

3.1. Study Sample. A total of 298 patients with diabetes on insulin were included for analysis. This included 133 patients with type 1 and 165 patients with type 2 diabetes. Of the 133 subjects with type 1 diabetes, 47 (35.3\%) were using an insulin pump and the rest were on multiple daily injections (MDI). The characteristics of the subjects including mean age, gender distribution, and diabetes duration are shown in Table 1 . The group with type 1 diabetes had a significantly lower age, BMI, and duration of diabetes as well as a significantly lower percentage of individuals suffering from hypertension, CAD, and nephropathy as compared to the group with type 2 diabetes. This group had a significantly higher mean $\mathrm{HbA1c}$, number of daily insulin injections, daily insulin dose, and SD around mean SMBG (indicator of glycemic variability) as compared to the group with type 2 diabetes. There was no statistically significant difference in regard to gender, daily insulin dose adjusted for BMI, and the percentage of individuals with depression or retinopathy between the two groups. The characteristics of the individuals with insulin-treated diabetes that were excluded from the study were similar to those that were included.

3.2. Frequency of Hypoglycemia. All patients with type 1 diabetes and $82 \%$ of patients with type 2 diabetes experienced at least one episode of hypoglycemia. The corresponding numbers for severe hypoglycemia were $68 \%$ for type 1 and $19 \%$ for type 2 diabetes. $88 \%$ of those with type 1 experienced more than 10 hypoglycemic episodes compared to $30 \%$ with type 2 diabetes. Those with type 1 diabetes recorded a total of 4583 hypoglycemic episodes that corresponds to a rate of 137.8 (95\% CI 135.9 and 139.8 ) episodes per person per year. 
TABLE 1: Characteristics of patients with insulin-treated diabetes participating in the study.

\begin{tabular}{|c|c|c|c|c|}
\hline Patient characteristics & $\begin{array}{c}\text { All patients } \\
\text { Mean } \pm \text { SD, range or } \\
n(\%) \text { patients } \\
\end{array}$ & $\begin{array}{c}\text { Type } 1 \text { diabetes } \\
\text { Mean } \pm \text { SD, range or } \\
n(\%) \text { patients } \\
\end{array}$ & $\begin{array}{c}\text { Type } 2 \text { diabetes } \\
\text { Mean } \pm \mathrm{SD} \text {, range or } \\
n(\%) \text { patients }\end{array}$ & $p$ value \\
\hline Number of patients (\%) & $298(100)$ & $133(44.6)$ & $165(55.4)$ & - \\
\hline Age (years) & $60.54 \pm 16.64$ & $52.11 \pm 17.19$ & $67.33 \pm 12.63$ & 0.001 \\
\hline Males & $153 / 145$ & $62(46.6)$ & $83(50)$ & 0.606 \\
\hline BMI $\left(\mathrm{kg} / \mathrm{m}^{2}\right)[$ mean $\pm \mathrm{SD}]$ & $30.38 \pm 7.45$ & $26.38 \pm 4.66$ & $33.58 \pm 7.73$ & 0.001 \\
\hline $\begin{array}{l}\text { Known duration of diabetes } \\
\text { (years) }[\text { mean } \pm S D]\end{array}$ & $21.43 \pm 14.62$ & $25.26 \pm 16.75$ & $18.11 \pm 11.58$ & 0.001 \\
\hline $\begin{array}{l}\text { Daily insulin dose (units/day) } \\
{[\text { mean } \pm \mathrm{SD}]}\end{array}$ & $66.48 \pm 56.05$ & $49.04 \pm 26.91$ & $74.59 \pm 63.80$ & 0.001 \\
\hline $\begin{array}{l}\text { Daily insulin dose } / \text { BMI } \\
\text { (units } / \mathrm{kg} / \mathrm{m}^{2} / \text { day) }[\text { mean } \pm \mathrm{SD}]\end{array}$ & $2.06 \pm 1.35(n=210)$ & $1.84 \pm 0.91(n=66)$ & $2.16 \pm 1.52(n=144)$ & 0.307 \\
\hline $\mathrm{HbAlc}(\%)[$ mean $\pm \mathrm{SD}]$ & \multirow{4}{*}{$7.77 \pm 1.25$} & $7.94 \pm 1.94$ & $7.64 \pm 1.27$ & \multirow{4}{*}{0.032} \\
\hline$<7$ & & $31(23.3)$ & $48(28.9)$ & \\
\hline $7-8$ & & $36(27.1)$ & $59(35.5)$ & \\
\hline$>8$ & & $66(49.6)$ & $58(34.9)$ & \\
\hline $\mathrm{SD}$ around mean SMBG & $68.71 \pm 17.04$ & $78.93 \pm 2.04$ & $60.47 \pm 1.69$ & 0.001 \\
\hline $\begin{array}{l}\text { Lowest } S M B G \text { reading } \\
{[\text { mean } \pm S D]}\end{array}$ & $49.69 \pm 15.78$ & $40.98 \pm 9.54$ & $56.71 \pm 16.33$ & 0.001 \\
\hline $\begin{array}{l}\text { Number of daily insulin } \\
\text { injections [mean } \pm \text { SD] }\end{array}$ & $\begin{array}{l}3.87 \pm 0.93(\text { median } 4 \\
\quad \text { range } 1-6)\end{array}$ & $\begin{array}{c}4.12 \pm 0.48(\text { median } 4 \\
\text { range } 2-6)\end{array}$ & $\begin{array}{l}3.73 \pm 1.08(\text { median } 4 \\
\text { range } 1-5)\end{array}$ & 0.001 \\
\hline MDI & & $86(64.7)$ & $165(100)$ & \multirow{2}{*}{-} \\
\hline Insulin pump & & $47(35.3)$ & None & \\
\hline HTN & $170(57.0)$ & $47(35.3)$ & $123(74.5)$ & 0.001 \\
\hline CAD & $74(24.8)$ & $19(14.3)$ & $55(33.3)$ & 0.001 \\
\hline Nephropathy & $102(34.2)$ & $27(20.3)$ & $75(45.2)$ & 0.001 \\
\hline Retinopathy $(n, \%)$ & $63(21.1)$ & $32(24.1)$ & $31(18.8)$ & 0.334 \\
\hline Depression $(n, \%)$ & $49(16.4)$ & $16(12.0)$ & $33(20.0)$ & 0.091 \\
\hline Caucasians $(n, \%)$ & $265(88.9)$ & $128(96.2)$ & $137(83.1)$ & 0.001 \\
\hline All hypoglycemic episodes & 6100 events & $\begin{array}{l}4583 \text { events in } 133(100 \%) \\
\text { patients }\end{array}$ & $\begin{array}{l}1517 \text { events in } 136(82 \%) \\
\text { patients }\end{array}$ & 0.000 \\
\hline $\begin{array}{l}\text { All hypoglycemic episodes per } \\
\text { person per year [OR }(95 \% \mathrm{CI})]\end{array}$ & $81.9(80.0$ to 82.9$)$ & $137.8(135.9$ to 139.8$)$ & $36.8(35.9$ to 37.7$)$ & 0.000 \\
\hline No hypoglycemic episodes & $29(9.7 \%)$ & $0(0 \%)$ & $29(17.6 \%)$ & - \\
\hline $\begin{array}{l}1-10 \text { hypoglycemic episodes in } \\
3 \text { months }\end{array}$ & $269(90.3 \%)$ & $16(12 \%)$ & $86(52.1 \%)$ & - \\
\hline $\begin{array}{l}>10 \text { hypoglycemic episodes in } \\
3 \text { months }\end{array}$ & $167(56.0 \%)$ & $117(88 \%)$ & $50(30.3 \%)$ & - \\
\hline Severe hypoglycemic episodes & 762 & $\begin{array}{l}643 \text { events in } 91(68 \%) \\
\text { patients }\end{array}$ & $\begin{array}{l}119 \text { events in } 32(19 \%) \\
\text { patients }\end{array}$ & 0.000 \\
\hline $\begin{array}{l}\text { Severe hypoglycemic episodes per } \\
\text { person per year [OR }(95 \% \mathrm{CI})]\end{array}$ & $10.2(9.9$ to 10.6$)$ & 19.3 (18.6 to 20.1$)$ & $2.9(2.6$ to 3.2$)$ & 0.000 \\
\hline No severe hypoglycemic episodes & $175(58.7 \%)$ & $42(31.6 \%)$ & $133(80.6 \%)$ & - \\
\hline $\begin{array}{l}1-10 \text { severe hypoglycemic episodes } \\
\text { in } 3 \text { months }\end{array}$ & $123(41.3 \%)$ & $73(54.9 \%)$ & $31(18.8 \%)$ & - \\
\hline $\begin{array}{l}>10 \text { severe hypoglycemic episodes } \\
\text { in } 3 \text { months }\end{array}$ & $19(6.4 \%)$ & $18(13.5 \%)$ & $1(0.6 \%)$ & - \\
\hline
\end{tabular}

$643(14 \%)$ of these were severe, corresponding to 19.3 (95\% CI 18.6 and 20.1) severe episodes per person per year. In those with type 2 diabetes, a total of 1517 hypoglycemic episodes were recorded; of which, 119 (8\%) were severe. This corresponds to an event rate per person per year for hypoglycemia and severe hypoglycemia of 36.8 (95\% CI 35.9, 37.7) and 2.9 (95\% CI 2.6, 3.2), respectively. Less than $1 \%$ of individuals with type 2 diabetes reported greater than 10 severe 
TABLE 2: Results of nonparametric test (Mann-Whitney $U$ test) for association of categorical independent variables with frequencies of hypoglycemia and severe hypoglycemia.

\begin{tabular}{|c|c|c|c|c|c|c|c|c|}
\hline \multirow{2}{*}{$\begin{array}{l}\text { Categorical variables } \\
\text { Mann-Whitney } U \text { test }\end{array}$} & \multicolumn{4}{|c|}{ Type 1 diabetes } & \multicolumn{4}{|c|}{ Type 2 diabetes } \\
\hline & $\begin{array}{c}\text { Hypoglycemia } \\
{[\text { mean } \pm \text { SD }]}\end{array}$ & $p$ value & $\begin{array}{c}\text { Severe hypoglycemia } \\
{[\text { mean } \pm \text { SD }]}\end{array}$ & $p$ value & $\begin{array}{c}\text { Hypoglycemia } \\
{[\text { mean } \pm \text { SD }]}\end{array}$ & $p$ value & $\begin{array}{c}\text { Severe hypoglycemia } \\
{[\text { mean } \pm \mathrm{SD}]}\end{array}$ & $p$ value \\
\hline Females & $37.96 \pm 26.40$ & \multirow{2}{*}{0.188} & $5.69 \pm 7.99$ & \multirow{2}{*}{0.523} & $8.16 \pm 9.96$ & \multirow{2}{*}{0.617} & $0.88 \pm 2.66$ & \multirow{2}{*}{0.412} \\
\hline Males & $30.45 \pm 19.31$ & & $3.85 \pm 5.22$ & & $10.22 \pm 11.91$ & & $0.57 \pm 1.72$ & \\
\hline Nephropathy absent & $36.45 \pm 24.62$ & \multirow{2}{*}{0.089} & $5.10 \pm 7.08$ & \multirow{2}{*}{0.162} & $9.57 \pm 11.84$ & \multirow{2}{*}{0.581} & $0.91 \pm 2.69$ & \multirow{2}{*}{0.487} \\
\hline Nephropathy present & $26.63 \pm 17.16$ & & $3.78 \pm 6.02$ & & $8.75 \pm 9.95$ & & $0.49 \pm 1.50$ & \\
\hline Retinopathy absent & $35.85 \pm 24.14$ & \multirow{2}{*}{0.258} & $4.94 \pm 7.03$ & \multirow{2}{*}{0.524} & $9.22 \pm 11.68$ & \multirow{2}{*}{0.109} & $0.81 \pm 2.43$ & \multirow{2}{*}{0.551} \\
\hline Retinopathy present & $30.06 \pm 21.49$ & & $4.50 \pm 6.46$ & & $9.06 \pm 7.53$ & & $0.35 \pm 1.02$ & \\
\hline On MDI & $32.92 \pm 23.43$ & \multirow{2}{*}{0.224} & $4.85 \pm 7.24$ & \multirow{2}{*}{0.543} & $9.30 \pm 11.02$ & \multirow{2}{*}{0.085} & $0.73 \pm 2.25$ & \multirow[t]{2}{*}{ - } \\
\hline On insulin pump & $37.28 \pm 23.84$ & & $4.81 \pm 6.23$ & & $0.50 \pm 0.71$ & & 0.00 & \\
\hline HTN absent & $35.23 \pm 24.09$ & \multirow{2}{*}{0.648} & $5.08 \pm 6.94$ & \multirow{2}{*}{0.377} & $10.48 \pm 11.60$ & \multirow{2}{*}{0.324} & $0.74 \pm 1.81$ & \multirow{2}{*}{0.647} \\
\hline HTN present & $33.04 \pm 22.79$ & & $4.38 \pm 6.80$ & & $8.76 \pm 10.80$ & & $0.71 \pm 2.37$ & \\
\hline CAD absent & $35.69 \pm 23.23$ & \multirow{2}{*}{0.063} & $5.12 \pm 7.09$ & \multirow{2}{*}{0.132} & $9.50 \pm 11.08$ & \multirow{2}{*}{0.367} & $0.76 \pm 2.42$ & \multirow{2}{*}{0.783} \\
\hline CAD present & $27.05 \pm 24.92$ & & $3.10 \pm 5.22$ & & $8.58 \pm 10.91$ & & $0.64 \pm 1.83$ & \\
\hline Other race & $24.60 \pm 11.33$ & \multirow{2}{*}{0.435} & $1.40 \pm 1.34$ & \multirow{2}{*}{0.284} & $10.11 \pm 12.25$ & \multirow{2}{*}{0.913} & $1.28 \pm 2.92$ & \multirow{2}{*}{0.326} \\
\hline Caucasians & $34.84 \pm 23.87$ & & $4.97 \pm 6.97$ & & $9.01 \pm 10.76$ & & $0.60 \pm 2.06$ & \\
\hline Depression absent & $34.63 \pm 24.07$ & \multirow{2}{*}{0.912} & $4.69 \pm 6.86$ & \multirow{2}{*}{0.484} & $8.56 \pm 10.72$ & \multirow{2}{*}{0.047} & $0.67 \pm 2.29$ & \multirow{2}{*}{0.366} \\
\hline Depression present & $33.19 \pm 20.21$ & & $5.87 \pm 7.13$ & & $11.73 \pm 11.89$ & & $0.94 \pm 2.03$ & \\
\hline $\begin{array}{l}\text { Different categories of } \\
\text { A1c }(<7,7-8,>8)\end{array}$ & & 0.001 & & 0.052 & & 0.507 & & 0.363 \\
\hline
\end{tabular}

TABLE 3: Results of nonparametric tests Spearman's correlation (to calculate correlation coefficient) and Wilcoxon signed-rank test (to assess significance with $p$ value) for association of continuous independent variables with frequencies of hypoglycemia and severe hypoglycemia.

\begin{tabular}{|c|c|c|c|c|c|c|c|c|}
\hline \multirow{3}{*}{ Continuous variables } & \multicolumn{4}{|c|}{ Type 1 diabetes } & \multicolumn{4}{|c|}{ Type 2 diabetes } \\
\hline & \multicolumn{2}{|c|}{ Hypoglycemia } & \multicolumn{2}{|c|}{ Severe hypoglycemia } & \multicolumn{2}{|c|}{ Hypoglycemia } & \multicolumn{2}{|c|}{ Severe hypoglycemia } \\
\hline & $\begin{array}{l}\text { Correlation } \\
\text { coefficient } \rho\end{array}$ & $p$ value & $\begin{array}{l}\text { Correlation } \\
\text { coefficient } \rho\end{array}$ & $p$ value & $\begin{array}{l}\text { Correlation } \\
\text { coefficient } \rho\end{array}$ & $p$ value & $\begin{array}{l}\text { Correlation } \\
\text { coefficient } \rho\end{array}$ & $p$ value \\
\hline Age (years) & -0.2 & 0.000 & -0.2 & 0.000 & -0.03 & 0.000 & -0.01 & 0.000 \\
\hline BMI & -0.1 & 0.005 & -0.1 & 0.000 & -0.1 & 0.000 & -0.2 & 0.000 \\
\hline Duration of diabetes & +0.2 & 0.000 & +0.2 & 0.000 & +0.2 & 0.000 & +0.2 & 0.000 \\
\hline Daily insulin dose & $0.1(n=66)$ & 0.003 & $0.1(n=46)$ & 0.000 & $0.1(n=119)$ & 0.000 & $0.01(n=29)$ & 0.000 \\
\hline Daily insulin injections & +0.2 & 0.000 & +0.2 & 0.14 & +0.04 & 0.000 & +0.1 & 0.000 \\
\hline Lowest $\mathrm{BG}$ reading & -0.7 & 0.006 & -0.9 & 0.000 & -0.8 & 0.000 & -0.7 & 0.000 \\
\hline $\mathrm{SD}$ around mean $\mathrm{BG}$ & +0.1 & 0.000 & +0.2 & 0.000 & +0.2 & 0.000 & +0.2 & 0.000 \\
\hline HbAlc & -0.4 & 0.000 & -0.2 & 0.000 & -0.1 & 0.456 & -0.04 & 0.000 \\
\hline
\end{tabular}

hypoglycemic episodes compared to almost $14 \%$ with type 1 diabetes. The frequencies of both all and severe hypoglycemic episodes were significantly higher for type 1 as compared to type 2 diabetes ( $p=0.000$ for both).

3.3. Predictors of Hypoglycemia in Type 1 Diabetes. On univariate analysis initially by correlation (for continuous variables) and then tests of significance (Tables 2 and 3), the frequencies of all and severe hypoglycemia had a significant negative association with the mean $\mathrm{HbA1c}(p=0.000$ for both), the lowest BG reading recorded ( $p=0.000$ for both), BMI ( $p=0.000$ for both), and age ( $p=0.000$ for both). The frequencies of all and severe hypoglycemia demonstrated a significant positive association with the duration of diabetes ( $p=0.000$ for both), daily insulin dose $(p=0.003$ and 0.000 , resp.), and glycemic variability ( $p=0.000$ for both). There was a positive association with the number of daily insulin injections that was statistically significant only for all hypoglycemia $(p=0.000)$.

Multivariate linear regression analysis (Table 4) which adjusted for independently associated variables revealed a significant positive association of the frequencies of all and severe hypoglycemia with glycemic variability and duration of diabetes and a significant negative association with HbAlc. When the lowest BG reading was included in this analysis, it continued to be significantly negatively associated 
TABLE 4: Multivariate regression analysis using hypoglycemic episodes and severe hypoglycemic episodes as dependent variables and variables that achieved significance on univariate analysis as independent variables.

\begin{tabular}{lcccc}
\hline $\begin{array}{l}\text { Variables significant on } \\
\text { univariate analysis }\end{array}$ & $\begin{array}{c}\text { Typoglycemia } \\
\text { (beta; } p \text { value) }\end{array}$ & $\begin{array}{c}\text { Severe hypoglycemia } \\
\text { (beta; } p \text { value) }\end{array}$ & $\begin{array}{c}\text { Hypoglycemia } \\
\text { (beta; } p \text { value) }\end{array}$ & $\begin{array}{c}\text { Severe hypoglycemia } \\
\text { (beta; } p \text { value) }\end{array}$ \\
\hline Age & $-0.25 ; 0.28$ & $-0.09 ; 0.23$ & $-0.26 ; 0.032$ & $-0.01 ; 0.84$ \\
BMI & $1.27 ; 0.14$ & $0.11 ; 0.71$ & $-0.27 ; 0.10$ & $-0.03 ; 0.41$ \\
Duration of diabetes & $0.46 ; 0.042$ & $0.16 ; 0.037$ & $0.18 ; 0.11$ & $-0.01 ; 0.65$ \\
Total insulin dose & $0.24 ; 0.11$ & $0.02 ; 0.72$ & $0.01 ; 0.74$ & $0.002 ; 0.79$ \\
Number of daily & $1.95 ; 0.76$ & - & $-0.89 ; 0.44$ & $0.05 ; 0.84$ \\
injections & $0.43 ; 0.022$ & $0.15 ; 0.023$ & $0.07 ; 0.22$ & $-0.01 ; 0.50$ \\
SD around mean BG & $-9.69 ; 0.010$ & $-3.19 ; 0.015$ & - & $-0.09 ; 0.71$ \\
HbAlc & - & - & $-1.63 ; 0.61$ & - \\
Depression & & &
\end{tabular}

with both all and severe hypoglycemia. The association with other variables like age, BMI, number of daily insulin injections, and daily insulin dose did not achieve significance in the regression analysis.

3.4. Predictors of Hypoglycemia in Insulin-Treated Type 2 Diabetes. On univariate analysis, the frequencies of all and severe hypoglycemia had a significant negative association with the lowest BG reading recorded ( $p=0.000$ for both), BMI ( $p=0.000$ for both), and age ( $p=0.000$ for both). There was a negative association with $\mathrm{HbAlc}$ that was statistically significant only for severe hypoglycemia $(p=0.000)$. The frequencies of all and severe hypoglycemia had a significant positive association with the duration of diabetes $(p=0.000$ for both), daily insulin dose ( $p=0.000$ for both), number of daily insulin injections ( $p=0.000$ for both), and glycemic variability ( $p=0.000$ for both). The frequency of all hypoglycemia had a significant positive association with the presence of depression $(p=0.047)$.

Multivariate linear regression analysis (Table 4), which adjusted for independently associated variables, revealed a significant negative association of the frequency of all hypoglycemia with age. The association with other variables seen on univariate analysis did not achieve significance during regression analysis. However, when the lowest BG reading was included in this analysis, it continued to be significantly negatively associated with both all and severe hypoglycemia, and the positive association of all hypoglycemia with glycemic variability achieved statistical significance.

When comparing individuals with type 1 diabetes using an insulin pump versus those on MDI, there was no statistically significant difference between the frequencies of all or severe hypoglycemia and mean $\mathrm{HbA} 1 \mathrm{C}$ value. In regard to different therapeutic regimens, there was no statistically significant difference in hypoglycemia frequency when comparing different MDI regimens for either type 1 or type 2 diabetes.

\section{Discussion}

Although hypoglycemia is a common complication of insulin treatment in diabetes, very few studies have evaluated the frequency and predictors of self-reported hypoglycemia on an ambulatory basis, especially in insulin-treated type 2 diabetes. The present study examined self-reported hypoglycemia in a sample of patients with insulin-treated diabetes who were being managed at a university hospital diabetes clinic and accurately represented the population base. Our results are based on hypoglycemia recorded by the subject whether or not they experienced symptoms. SMBG frequency of at least 3 times a day reduced the likelihood of missing any episodes of hypoglycemia. The over recording of hypoglycemia in the initial data was corrected by counting SMBG readings $\leq 70 \mathrm{mg} / \mathrm{dL}$ recorded within a 2 -hour period as one hypoglycemic episode unless there was a reading $>70 \mathrm{mg} / \mathrm{dL}$ in between them. It is not surprising that our patients with type 1 diabetes reported more hypoglycemic episodes as compared to those with type 2 diabetes. However, compared with previous studies of both type 1 $[19,20]$ and type 2 diabetes $[11,14,21]$, the event rates and the proportion of subjects experiencing hypoglycemic events in our study were higher, especially in type 2 diabetes with $19 \%$ experiencing an episode of severe hypoglycemia. The possible reasons for this could be the longer duration of diabetes in our patients, being followed on an ambulatory basis as compared to being enrolled in a clinical trial, and the fact that many other studies have defined severe hypoglycemia on symptoms and not BG values. The rates of severe hypoglycemia in insulin-treated type 2 diabetes are reported to be low $[11,14,21]$, but these have been recorded in the context of clinical trials and often in people with a short duration of insulin therapy.

Insulin use has been linked to higher likelihood of experiencing hypoglycemia; however, within the group of insulin-treated diabetes, the predictors of hypoglycemia remain unclear. In type 1 diabetes, a negative association of hypoglycemia with $\mathrm{HbA1c}$ has been reported by several studies $[15,22,23]$. In type 2 diabetes, either no association or a positive association of hypoglycemia with $\mathrm{HbA1c}$ has been reported $[8,20,24]$ except in the PREDICTIVE trial which demonstrated a negative association between the two in both type 1 and type 2 diabetes [23]. Within the intensive treatment arm of the ACCORD trial for type 2 diabetes, a higher $\mathrm{HbAlc}$ and lower change in HbAlc from baseline were 
associated with a higher rate of occurrence of hypoglycemia [25]. In our study, after adjusting for independent variables, lower HbAlc was a potential predictor of hypoglycemia in type 1 but not in type 2 diabetes. Glycemic variability has been assessed by studies using different parameters, SD around mean BG being the best demonstrated for SMBG data. In our study, this was a significant predictor for hypoglycemia. A history of previous severe hypoglycemia has been reported to be a risk factor for severe hypoglycemia $[15,26]$. Similarly, our study found a significant association between experiencing a low PG reading and increased frequency of all and severe hypoglycemic episodes in both type 1 and type 2 diabetes. Also, the distribution of hypoglycemia in our study was highly skewed with a small proportion of patients accounting for the majority of episodes.

In the UKPDS trial, hypoglycemia was more frequent in younger patients, females, non-obese patients and those with positive islet cell antibodies [11]. Our study also showed a higher frequency of hypoglycemia in younger type 2 diabetes patients, but there was no significant association with gender or BMI in regression analysis. However these two studies are not exactly comparable as we studied only insulin-treated diabetics with longer diabetes duration. Other studies have reported hypoglycemia in type 2 diabetes to be linked to longer duration of diabetes $[7,20]$ which we found on univariate but not multivariate analysis. The increased occurrence of hypoglycemia in patients with longer duration of diabetes could be related to the accompanying hypoglycemiaassociated autonomic failure (HAAF). Depression has been associated with severe hypoglycemia in type 2 diabetes [27]; in our study, this association was observed on univariate analysis but did not hold up in multivariate regression analysis. In type 2 diabetes, a lower BMI is associated with hypoglycemia in some studies [23], and in our cohort, this relationship was observed only in univariate, but not in multivariate analysis. Our observation of higher rates of hypoglycemia in younger type 2 diabetes patients can be explained by the higher insulin sensitivity in this group. There was no significant difference in the frequency of hypoglycemia or mean $\mathrm{HbA1c}$ between those with type 1 diabetes that were on an insulin pump versus those on MDI; however the study was not powered to assess this. Similar findings have been reported by a recent meta-analysis [28].

\section{Conclusions}

Insulin treatment of diabetes increases the likelihood of experiencing hypoglycemia. We studied a cohort of patients with relatively well-controlled diabetes in terms of their HbA1c values, who had diabetes for a long duration thus increasing their risk of HAAF. Even though hypoglycemia is more common in type 1 diabetes, it continues to remain an important complication of insulin treatment in type 2 diabetes. In type 1 diabetes, striving for a lower HbAlc increases the risk of hypoglycemia. In addition, increased glycemic variability and longer duration of diabetes are significant potential predictors of hypoglycemia. In type 2 diabetes, factors predisposing to hypoglycemia are interdependent and we found it difficult to delineate them separately. However, we did find higher glycemic variability to be associated with a higher frequency of hypoglycemic episodes in this group. There seems to be a positive association of hypoglycemia with depression in type 2 diabetes, which needs to be further explored. In our study, younger insulin-treated type 2 diabetics experienced more hypoglycemic episodes, which is contrary to some other studies. Experiencing a hypoglycemic episode increases the risk of more hypoglycemia in both type 1 and type 2 diabetes. Very frequent hypoglycemia occurs in a small proportion of patients, and these are the ones that require the greatest attention to avoid hypoglycemia. Glycemic variability, which is an indicator of poor glycemic control rather than tight glycemic control, portends increased risk for hypoglycemia. Studies that focus on glycemic variability and interventions to prevent hypoglycemia in high-risk patients are needed.

\section{Disclosure}

The initial abstract for this study was published as part of ADA 75th scientific sessions [29].

\section{Conflicts of Interest}

The authors have no conflicts of interest to disclose.

\section{Authors' Contributions}

Anupam Kotwal researched the data, performed data analysis, and prepared the manuscript. Samir Malkani supervised the project and reviewed and edited the manuscript.

\section{Acknowledgments}

The authors thank Louise Maranda for her help with data analysis.

\section{References}

[1] C. J. Thompson, J. F. Cummings, J. Chalmers, C. Gould, and R. W. Newton, "How have patients reacted to the implications of the DCCT?," Diabetes Care, vol. 19, pp. 876-879, 1996.

[2] R. A. Whitmer, A. J. Karter, K. Yaffe, C. P. Quesenberry Jr., and J. V. Selby, "Hypoglycemic episodes and risk of dementia in older patients with type 2 diabetes mellitus," JAMA, vol. 301, pp. 1565-1572, 2009.

[3] A. Goto, O. A. Arah, M. Goto, Y. Terauchi, and M. Noda, "Severe hypoglycaemia and cardiovascular disease: systematic review and meta-analysis with bias analysis," BMJ (Clinical Research Edition), vol. 347, article f4533, 2013.

[4] P. E. Cryer, "Severe hypoglycemia predicts mortality in diabetes," Diabetes Care, vol. 35, pp. 1814-1816, 2012.

[5] L. Razavi Nematollahi, A. E. Kitabchi, F. B. Stentz et al., "Proinflammatory cytokines in response to insulin-induced hypoglycemic stress in healthy subjects," Metabolism, vol. 58, pp. 443-448, 2009.

[6] W. Duckworth, C. Abraira, T. Moritz et al., "Glucose control and vascular complications in veterans with type 2 diabetes," The New England Journal of Medicine, vol. 360, pp. 129-139, 2009. 
[7] L. Monnier, A. Wojtusciszyn, C. Colette, and D. Owens, "The contribution of glucose variability to asymptomatic hypoglycemia in persons with type 2 diabetes," Diabetes Technology \& Therapeutics, vol. 13, pp. 813-818, 2011.

[8] T. M. Davis, S. G. Brown, I. G. Jacobs, M. Bulsara, D. G. Bruce, and W. A. Davis, "Determinants of severe hypoglycemia complicating type 2 diabetes: the Fremantle diabetes study," The Journal of Clinical Endocrinology and Metabolism, vol. 95, pp. 2240-2247, 2010.

[9] D. Tschope, P. Bramlage, C. Binz, M. Krekler, E. Deeg, and A. K. Gitt, "Incidence and predictors of hypoglycaemia in type 2 diabetes - an analysis of the prospective DiaRegis registry," BMC Endocrine Disorders, vol. 12, pp. 1472-6823, 2012.

[10] ORIGIN Trial Investigators, "Predictors of nonsevere and severe hypoglycemia during glucose-lowering treatment with insulin glargine or standard drugs in the ORIGIN trial," Diabetes Care, vol. 38, pp. 22-28, 2015.

[11] A. D. Wright, C. A. Cull, K. M. Macleod, and R. R. Holman, "Hypoglycemia in type 2 diabetic patients randomized to and maintained on monotherapy with diet, sulfonylurea, metformin, or insulin for 6 years from diagnosis: UKPDS73," Journal of Diabetes and Its Complications, vol. 20, pp. 395-401, 2006.

[12] K. Akram, U. Pedersen-Bjergaard, K. Borch-Johnsen, and B. Thorsteinsson, "Frequency and risk factors of severe hypoglycemia in insulin-treated type 2 diabetes: a literature survey," Journal of Diabetes and Its Complications, vol. 20, pp. 402408, 2006.

[13] C. D. Miller, L. S. Phillips, D. C. Ziemer, D. L. Gallina, C. B. Cook, and I. M. El-Kebbi, "Hypoglycemia in patients with type 2 diabetes mellitus," Archives of Internal Medicine, vol. 161, pp. 1653-1659, 2001.

[14] C. Abraira, J. A. Colwell, F. Q. Nuttall et al., "Veterans affairs cooperative study on glycemic control and complications in type II diabetes (VA CSDM). Results of the feasibility trial. Veterans affairs cooperative study in type II diabetes," Diabetes Care, vol. 18, pp. 1113-1123, 1995.

[15] "The effect of intensive treatment of diabetes on the development and progression of long-term complications in insulin-dependent diabetes mellitus. The Diabetes Control and Complications Trial Research Group," The New England Journal of Medicine, vol. 329, pp. 977-986, 1993.

[16] E. Chow, A. Bernjak, S. Williams et al., "Risk of cardiac arrhythmias during hypoglycemia in patients with type 2 diabetes and cardiovascular risk," Diabetes, vol. 63, pp. 17381747, 2014.

[17] E. R. Seaquist, J. Anderson, B. Childs et al., "Hypoglycemia and diabetes: a report of a workgroup of the American Diabetes Association and the Endocrine Society," Diabetes Care, vol. 36, pp. 1384-1395, 2013.

[18] K. Tonyushkina and J. H. Nichols, "Glucose meters: a review of technical challenges to obtaining accurate results," Journal of Diabetes Science and Technology, vol. 3, pp. 971-980, 2009.

[19] U. Pedersen-Bjergaard, S. Pramming, S. R. Heller et al., "Severe hypoglycaemia in 1076 adult patients with type 1 diabetes: influence of risk markers and selection," Diabetes/Metabolism Research and Reviews, vol. 20, pp. 479-486, 2004.

[20] L. A. Donnelly, A. D. Morris, B. M. Frier et al., "Frequency and predictors of hypoglycaemia in type 1 and insulin-treated type 2 diabetes: a population-based study," Diabetic Medicine, vol. 22, pp. 749-755, 2005.
[21] UK Hypoglycaemia Study Group, "Risk of hypoglycaemia in types 1 and 2 diabetes: effects of treatment modalities and their duration," Diabetologia, vol. 50, pp. 1140-1147, 2007.

[22] E. S. Kilpatrick, A. S. Rigby, K. Goode, and S. L. Atkin, "Relating mean blood glucose and glucose variability to the risk of multiple episodes of hypoglycaemia in type 1 diabetes," Diabetologia, vol. 50, pp. 2553-2561, 2007.

[23] H. J. Luddeke, S. Sreenan, S. Aczel et al., "PREDICTIVE - a global, prospective observational study to evaluate insulin detemir treatment in types 1 and 2 diabetes: baseline characteristics and predictors of hypoglycaemia from the European cohort," Diabetes, Obesity \& Metabolism, vol. 9, pp. 428-434, 2007.

[24] M. E. Miller, D. E. Bonds, H. C. Gerstein et al., "The effects of baseline characteristics, glycaemia treatment approach, and glycated haemoglobin concentration on the risk of severe hypoglycaemia: post hoc epidemiological analysis of the ACCORD study," BMJ, vol. 8, 2010.

[25] M. E. Miller, D. E. Bonds, H. C. Gerstein et al., "The effects of baseline characteristics, glycaemia treatment approach, and glycated haemoglobin concentration on the risk of severe hypoglycaemia: post hoc epidemiological analysis of the ACCORD study," BMJ, vol. 340, article b5444, 2010.

[26] S. Bott, U. Bott, M. Berger, and I. Muhlhauser, "Intensified insulin therapy and the risk of severe hypoglycaemia," Diabetologia, vol. 40, pp. 926-932, 1997.

[27] Y. Kikuchi, M. Iwase, H. Fujii et al., "Association of severe hypoglycemia with depressive symptoms in patients with type 2 diabetes: the Fukuoka Diabetes Registry," BMJ Open Diabetes Research \& Care, vol. 3, article e000063, 2015.

[28] M. M. Fatourechi, Y. C. Kudva, M. H. Murad, M. B. Elamin, C. C. Tabini, and V. M. Montori, "Clinical review: hypoglycemia with intensive insulin therapy: a systematic review and meta-analyses of randomized trials of continuous subcutaneous insulin infusion versus multiple daily injections," The Journal of Clinical Endocrinology and Metabolism, vol. 94, pp. 729-740, 2009.

[29] A. Kotwal, T. English, and S. Malkani, "Potential predictors of hypoglycemia in type 1 and type 2 diabetes," Diabetes, vol. 64, Supplement 1, article A102, 2015. 


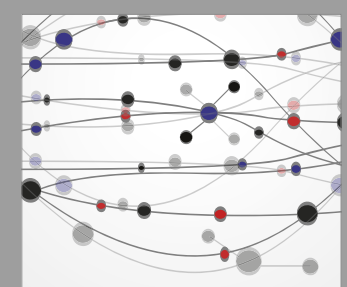

The Scientific World Journal
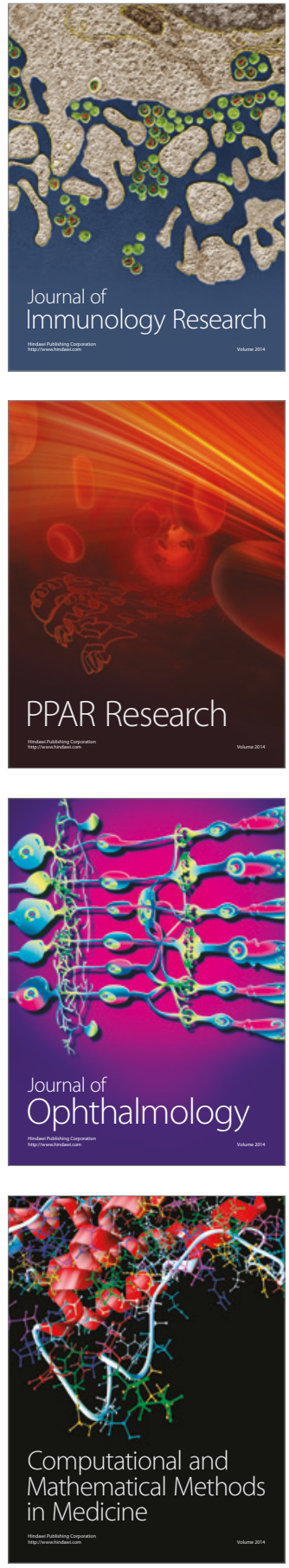

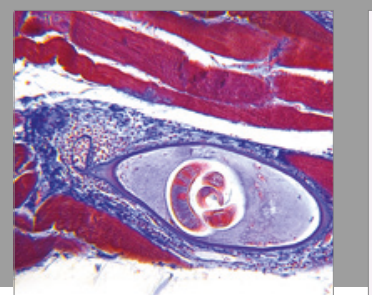

Gastroenterology Research and Practice
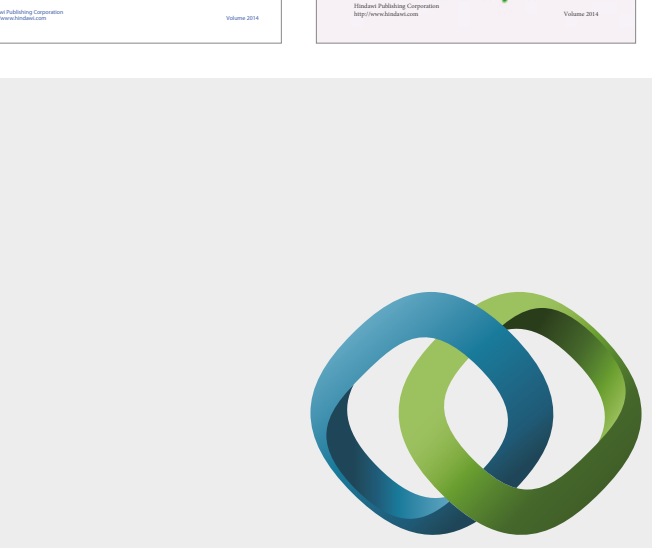

\section{Hindawi}

Submit your manuscripts at

https://www.hindawi.com
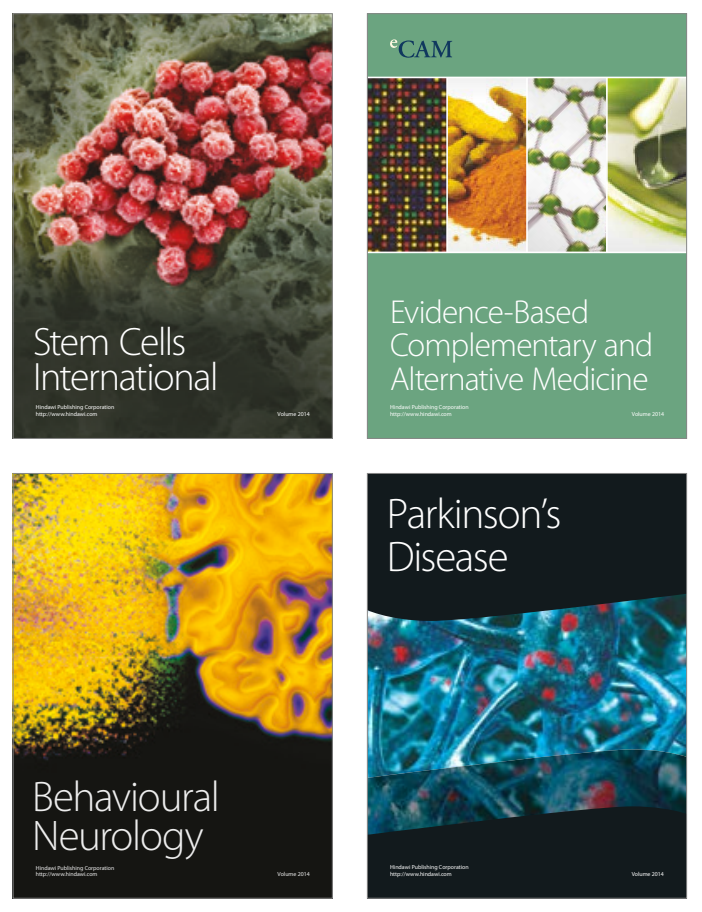
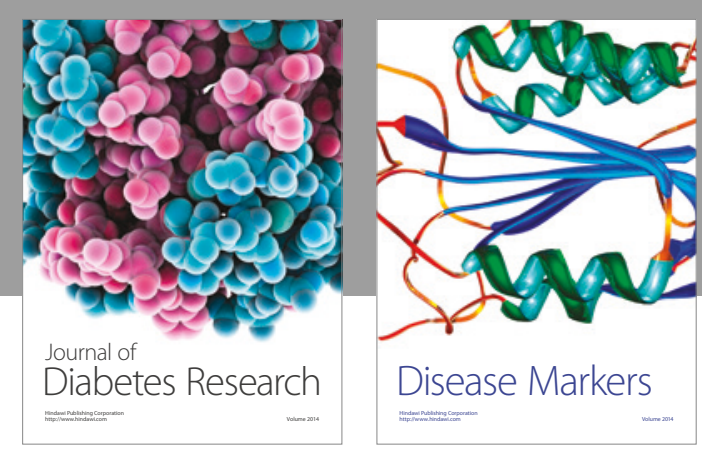

Disease Markers
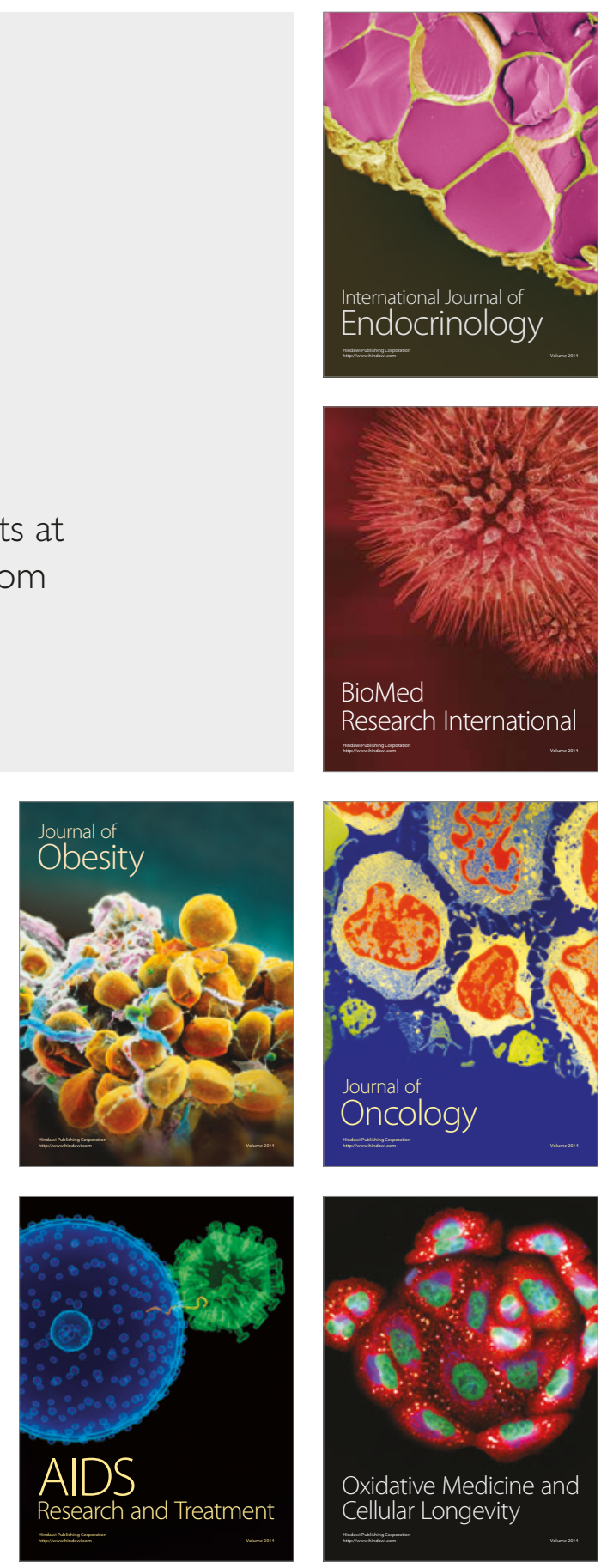